\title{
Rock Magnetic Cyclostratigraphy of the Carboniferous Mauch Chunk Formation, Pottsville, PA, United States
}

\author{
Kenneth P. Kodama* \\ Department of Earth and Environmental Sciences, Lehigh University, Bethlehem, PA, United States
}

A rock magnetic cyclostratigraphy study was conducted on the Carboniferous Mauch Chunk Formation red beds at Pottsville, Pennsylvania to determine if Milankovitch climate forcing could be detected in these terrestrial, fluvial deposits with hematite as the predominant ferromagnetic mineral. Because fluvial deposits are not deposited continuously it would be important to determine if they could record Milankovitch-scale climate cycles. Furthermore, the hematite magnetic mineral particles in red beds are

OPEN ACCESS

Edited by:

Emilio L. Pueyo,

Geological and Mining Institute

of Spain, Spain

Reviewed by:

Ann Marie Hirt,

ETH Zürich, Switzerland

Fatima Martin Hernandez,

Complutense University of Madrid,

Spain

Juan Cruz Larrasoaña,

Geological and Mining Institute of Spain, Spain

*Correspondence:

Kenneth P. Kodama kpk0@lehigh.edu

Specialty section:

This article was submitted to Geomagnetism and Paleomagnetism,

a section of the journal

Frontiers in Earth Science

Received: 06 August 2019

Accepted: 18 October 2019

Published: 12 November 2019

Citation:

Kodama KP (2019) Rock

Magnetic Cyclostratigraphy of the

Carboniferous Mauch Chunk

Formation, Pottsville, PA, United

States. Front. Earth Sci. 7:285.

doi: 10.3389/feart.2019.00285 not always recognized as primary, depositional minerals, so it was unclear whether they could record Milankovitch climate cycles. This locality was chosen because a robust magnetostratigraphy had already been established for it thus giving an estimate of its sediment accumulation rate (SAR). Magnetic susceptibility was measured in the laboratory with a KLY-3s Kappabridge on samples collected every $0.5 \mathrm{~m}$ of section for $68 \mathrm{~m}$ of section. Magnetic susceptibility measurements were also made in the field using an SM-20 portable susceptibility meter. The time series that resulted were different but yielded very similar power spectra calculated by the multi-taper method (MTM). Significant spectral peaks isolated by robust red noise and harmonic f-tests yielded peaks identified to be short eccentricity (125 and $95 \mathrm{ka}$ ), obliquity (35 ka) and precession (21 and $17.5 \mathrm{ka}$ ) in the Carboniferous. Average spectral misfit (ASM) analysis of these peaks for both the Kappabridge and SM-20 time series gave the identical SAR of $5.69 \mathrm{~cm} / \mathrm{ka}$, somewhat slower than the $\sim 9 \mathrm{~cm} / \mathrm{ka}$ average rate for $>250 \mathrm{~m}$ of section estimated from magnetostratigraphy and biostratigraphic correlation throughout northeastern North America. Analysis of the low temperature magnetic susceptibility versus temperature curves for a $10 \mathrm{~m}$ stratigraphic interval of samples indicates that the ferromagnetic content of the bulk susceptibility appears to be driving the precessionand obliquity-scale bulk susceptibility variations. This observation suggests that climate change in the source area causes more or less erosion of ferromagnetic minerals that are then deposited into a background of paramagnetic clays or diamagnetic quartz sand in the depositional basin. Our study clearly shows that fluvial terrestrial sediments can record astronomically forced climate change. Our study also indicates that portable susceptibility measurements are a valid way of collecting reconnaissance rock magnetic time series to determine sampling intervals for more detailed studies.

Keywords: cyclostratigraphy, rock magnetism, Milankovitch cycle, magnetic susceptibility, Mauch Chunk Formation 


\section{INTRODUCTION}

Rock magnetic cyclostratigraphy (Kodama and Hinnov, 2015) uses rock magnetic measurements of sedimentary sequences to detect astronomically forced global climate change cycles thus allowing high-resolution chronostratigraphy to be assigned to the sequence. To date most successful rock magnetic cyclostratigraphy studies have been conducted on marine sediments (Kodama et al., 2010; Gunderson et al., 2012; Wu et al., 2012; Hinnov, 2013; Minguez et al., 2015; Gong et al., 2017; Minguez and Kodama, 2017; Pas et al., 2018) which have a greater probability of nearly continuous sedimentation; therefore, ensuring a more complete record of global climate cycles.

The goal of this study of the Carboniferous Mauch Chunk Formation red beds is to determine if rock magnetics can detect astronomically forced global climate cycles in a terrestrial, fluvial depositional environment that doesn't have continuous sedimentation. There have been few cyclostratigraphic studies of terrestrial environments (Abdul Aziz et al., 2000; Abels et al., 2013; Noorbergen et al., 2018; Zhang et al., 2019). There is the additional concern that a red bed, dominated by the antiferromagnetic mineral hematite, may not have a depositional remanence, although the Mauch Chunk has demonstrated a robust magnetostratigraphy (DiVenere and Opdyke, 1991) so it either carries a depositional remanence or a very early diagenetic (chemical) remanence. Additional paleomagnetic studies of the Mauch Chunk Formation (Kent and Opdyke, 1985; Stamatakos and Kodama, 1991; Cioppa and Kodama, 2003; Bilardello and Kodama, 2010) strongly suggest, in particular for the anisotropy/inclination shallowing detection and correction work, that the magnetization is a depositional remanence carried by the hematite grains.

Our specific target was the Pottsville, Pennsylvania outcrop of the Mauch Chunk Formation. It is located in east central Pennsylvania and has been described in detail by Levine and Slingerland (1987) (Figure 1). The Pottsville outcrop, exposed along Route 61 just south of Pottsville, PA is approximately $600 \mathrm{~m}$ thick. We sampled the bottom $68 \mathrm{~m}$ of this section which, according to Levine and Slingerland, is comprised of overbank deposits (red calcareous mudstones) and shallow channel deposits (coarse to fine-grained red sandstones). Slingerland and Levine identify upward fining sequences from sandstone to mudstone repeating about every $20 \mathrm{~m}$ in this part of the section.

The Pottsville outcrop of the Mauch Chunk also offers a detailed magnetostratigraphy (DiVenere and Opdyke, 1991) which allows constraint of the sediment accumulation rate (SAR) thus allowing more robust identification of any Milankovitch cycles detected by the rock magnetics. The DiVenere and Opdyke (1991) magnetostratigraphy identifies a long (100 m thick) normal polarity event in the bottom part of the section where we have sampled. This normal event (MMCn at the Pottsville section) has been correlated to N5 in the Nova Scotia's Maringouin Peninsula and the Joggins section and the MPN1 at the Broad Cove-Chapel section in Cape Breton Island by Opdyke et al. (2014) based primarily on biostratigraphy (palynology and fossil plants). This correlation suggests that $270.5 \mathrm{~m}$ of the Pottsville section represents 2.9 million years
(Opdyke et al., 2014) yielding an average SAR of $9.3 \mathrm{~cm} / \mathrm{ka}$. The Geologic Time Scale 2012 (Gradstein et al., 2012) indicates that the MMCn normal polarity event is a little less than one million years in duration $(\mathrm{SAR} \sim 9-10 \mathrm{~cm} / \mathrm{ka}$ ) and is $330.9 \mathrm{Ma}$ in age.

This paper will demonstrate that Milankovitch cycles (astronomically forced global climate change cycles of periodicities 100,35 , and $\sim 20 \mathrm{ka}$ ) can be detected rock magnetically in a fluvial depositional environment despite the presence of hiatuses in sedimentation typical of this environment. We will also show that measuring the susceptibility in the field with a portable susceptibility meter can yield a time series which records the same Milankovitch cycles.

\section{MATERIALS AND METHODS}

To acquire the rock magnetic time series, we collected an un-oriented sample every $0.5 \mathrm{~m}$ of stratigraphic thickness, measuring stratigraphic thickness with a Jacob's staff for the nearly vertically dipping strata at the Pottsville section. Based on the time series analysis theory, the shortest cycle detectable is the Nyquist frequency which is determined by the sample spacing.

$$
\text { Nyquist frequency }=1 /(2 \times \text { sample spacing })
$$

The shortest Milankovitch frequency we hoped to detect is precession which has periodicities of about 17.5 and $21 \mathrm{ka}$ in the Carboniferous (Berger and Loutre, 1994; Waltham, 2015). Based on the SAR estimated from biostratigraphy and magnetostratigraphy $(9.3 \mathrm{~cm} / \mathrm{ka})$, this would dictate sampling about every $80 \mathrm{~cm}$ of stratigraphic thickness to detect precession. Conservatively, we sampled every $50 \mathrm{~cm}$.

In a pilot study, in 2012, a graduate level paleomagnetism class at Lehigh University sampled $40 \mathrm{~m}$ of the Pottsville section and measured isothermal remanent magnetization (IRMs) acquired in a $3.5 \mathrm{~T}$ field $\left(\mathrm{IRM}_{3.5 \mathrm{~T}}\right)$. The measurements were normalized by sample mass. The magnetic susceptibility $(X)$ was also measured and the IRMs were alternating field demagnetized at $100 \mathrm{mT}$ to remove the contributions of low coercivity ferromagnetic minerals to the

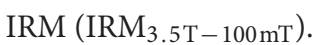

In 2017, un-oriented samples were collected from $68 \mathrm{~m}$ of section, at a $0.5 \mathrm{~m}$ spacing. The rock samples were fitted into $2 \times 2 \times 2 \mathrm{~cm}^{3}$ plastic sample cubes and their magnetic susceptibility was measured in a KLY-3s Kappabridge. Each sample was measured three times and the measurements were averaged. The average measurements for each sample were normalized by sample mass. In the 2017 study, an SM-20 portable susceptibility meter was used to measure the bulk susceptibility at each place on the outcrop that the un-oriented samples were collected. The in situ susceptibility was measured at least three times on the flattest surface available and the results were averaged. The measurement is normalized by the volume that the SM-20 measures, approximately $49 \mathrm{~cm}^{3}$. The stratigraphic measurements were tied to the bottom of the Mauch Chunk Formation which outcrops at the Pottsville section. 


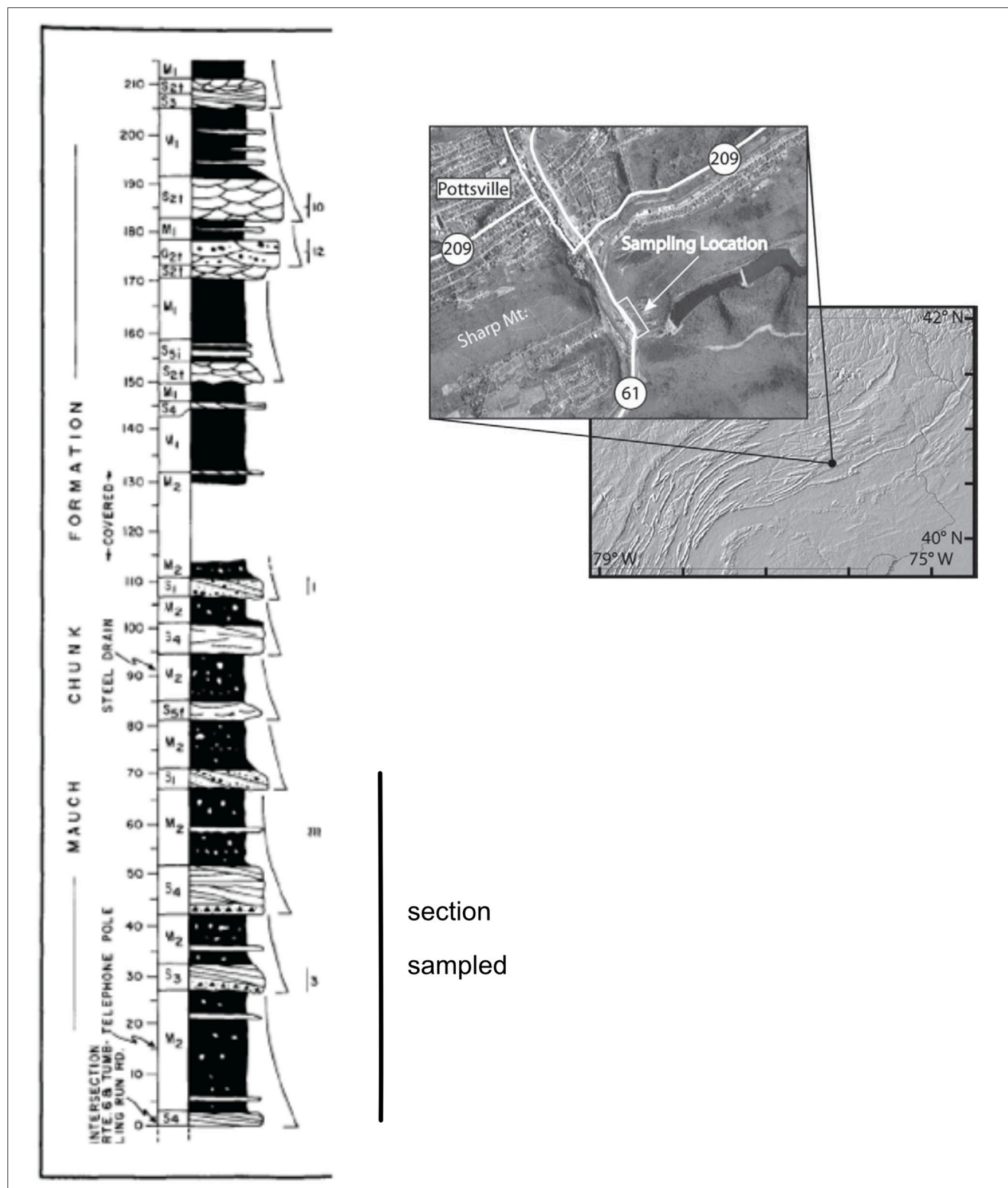

FIGURE 1 | (Left) Stratigraphic column of the Pottsville, PA, Mauch Chunk Formation section from Levine and Slingerland (1987). (Right) Location of the Pottsville section of the Mauch Chunk Formation along Route 61 in northeastern Pennsylvania (from Bilardello and Kodama, 2010). 
Time series analysis was conducted using the multi-taper method (MTM, Thomson, 1982) with robust (Mann and Lees, 1996) red noise [Gilman et al., 1963; AR-1 autoregressive for both the portable (SM-20) and un-oriented rock samples (Kappabridge)]. Meyers' (2014) and RStudio Team. (2015) was used for the analyses. Evolutionary spectrograms, using Astrochron, were also calculated to monitor how the dominant cycles varied throughout the section.

In the Astrochron time series analysis, outliers were trimmed from the time series using a box and whisker plot to reduce noise, the time series was resampled at an even spacing using linear interpolation, and MTM spectral analysis was conducted. In the

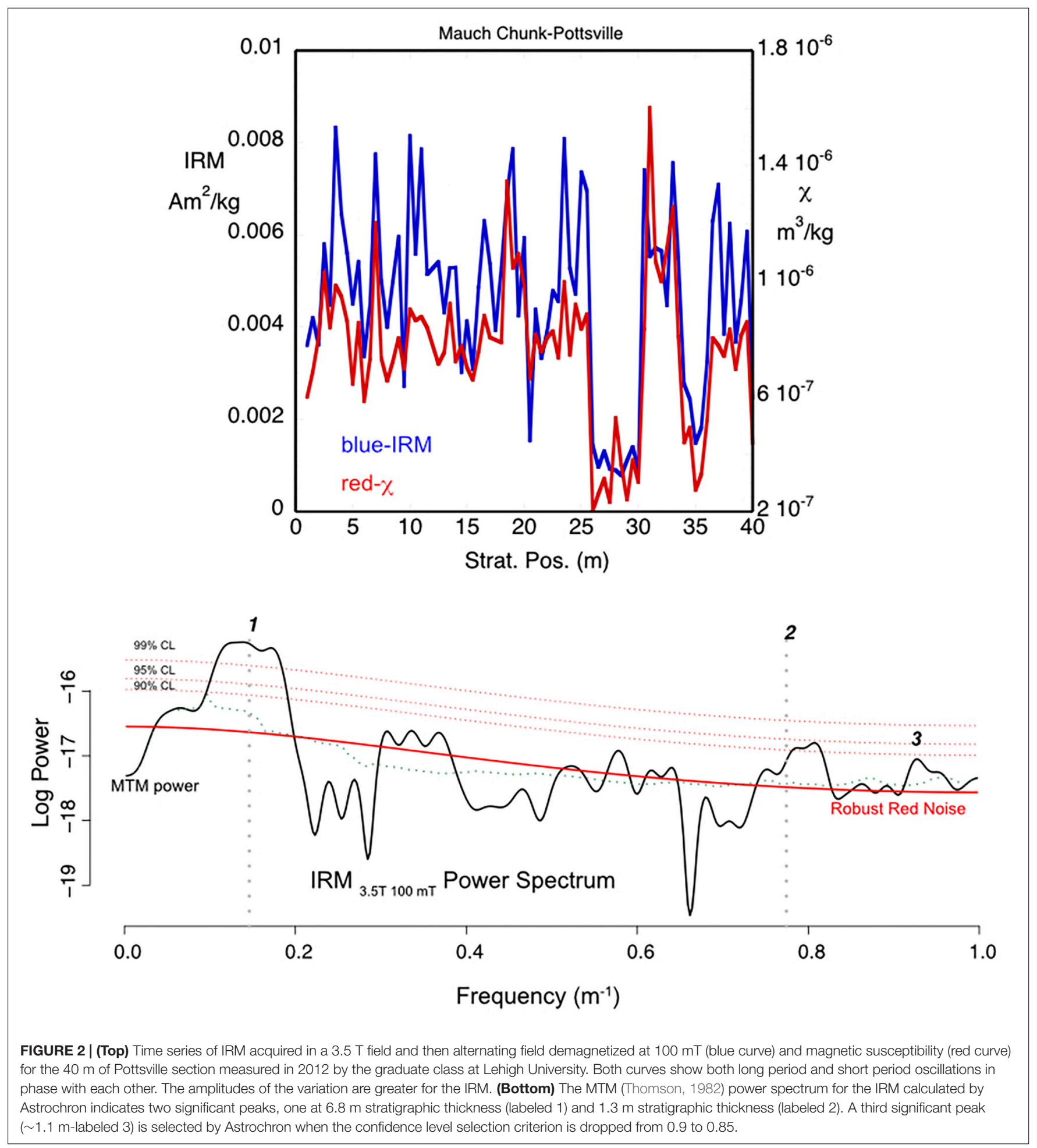


MTM analysis 3 DPSS tapers were used, the mean was subtracted, the data were detrended and zero padded by a factor of 10 . AR-1 robust red noise was calculated. Astrochron automatically identifies spectral peaks that are greater than a set value for the confidence level of the robust red noise and the harmonic f-test calculated by the MTM method (Meyers, 2012). The confidence levels were set at the default value (0.9) for the SM-20 time series and 0.85 for the Kappabridge time series.

To check our identification of the Milankovitch cycles, we conducted amplitude modulation (AM) analysis of the cycle we chose to be precession. The time series was filtered at the suspected precession frequency and time series analysis of the amplitude envelope of the filtered series was used to determine if there were cycles at the eccentricity time scale, because eccentricity modulates precession.

Low temperature (liquid $\mathrm{N}$ temperature, $-195^{\circ} \mathrm{C}$, warmed to $0^{\circ} \mathrm{C}$ ) magnetic susceptibility versus temperature (MS vs. T) measurements were made in the KLY-3s Kappabridge to determine the proportion of paramagnetic (clays) and ferromagnetic (hematite and/or magnetite) minerals carrying the magnetic susceptibility. This was done following the constant ferromagnetic susceptibility

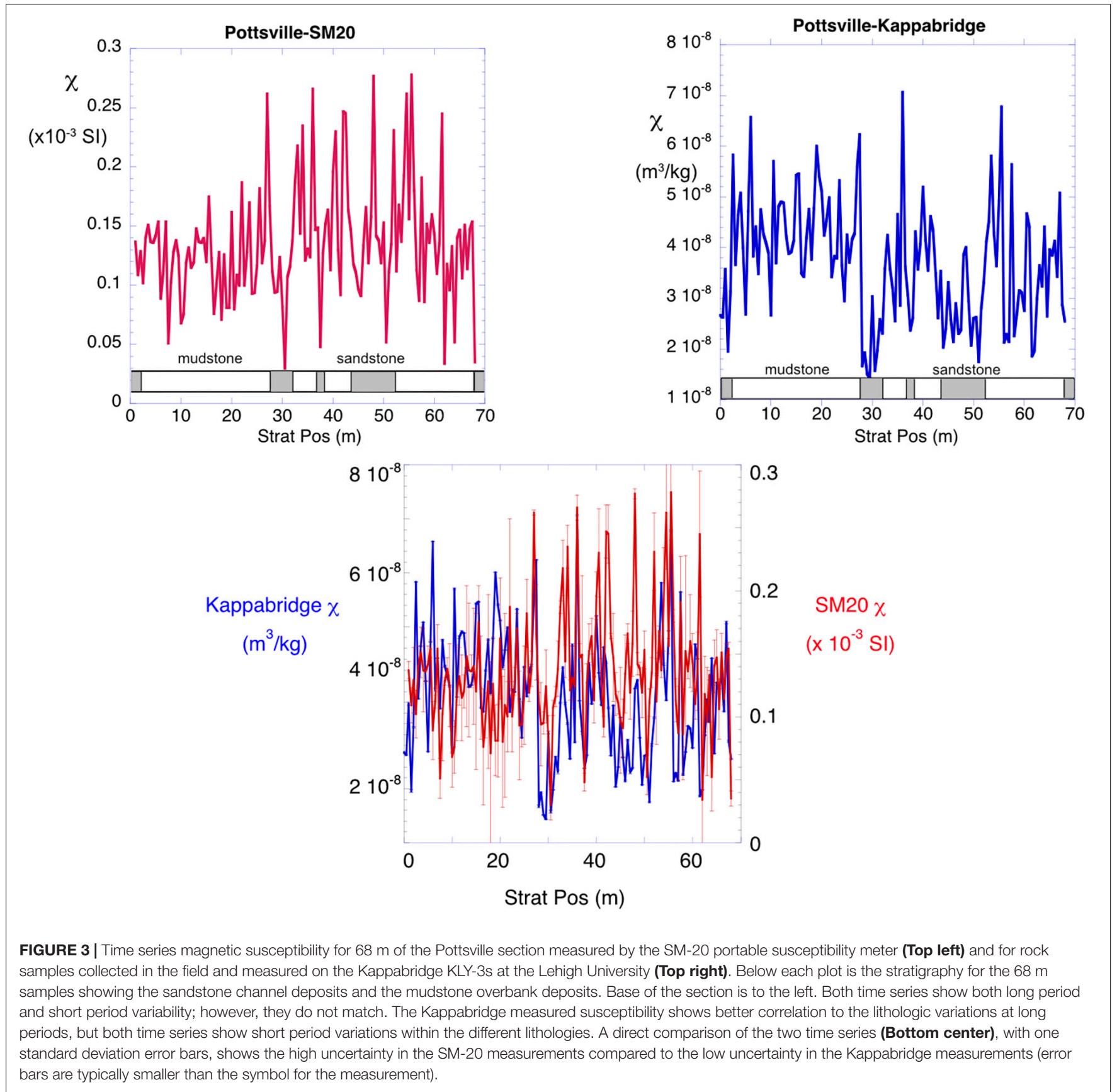


method of Hrouda (1994) in which a hyperbola is fit to the magnetic susceptibility measured as the sample warmed from -195 to $0^{\circ} \mathrm{C}$. The goodness of fit determines the percentage of paramagnetic minerals contributing to the bulk susceptibility. High temperature MS vs. $\mathrm{T}$ measurements in an argon atmosphere cycled up to $700^{\circ} \mathrm{C}$ and back down to room temperature were used to identify the ferromagnetic minerals.

Isothermal remanent magnetization acquisition experiments were also conducted to identify the ferromagnetic minerals in the samples. The IRM acquisition data were modeled using the Kruiver et al. (2001) Excel spreadsheet available from the Fort Hoofddijk paleomagnetic laboratory website.
All remanence measurements were conducted in a $2 \mathrm{G}$ Enterprises superconducting rock magnetometer (model 755) in a magnetically shielded room with a background magnetic field of $\sim 350 \mathrm{nT}$.

\section{RESULTS}

\section{Spectral Analysis}

The time series constructed from IRM and MS measurements in the 2012 pilot study show a strong correlation between IRM $_{3.5}$ T,

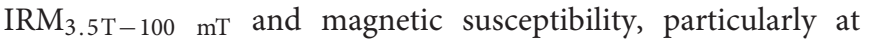
stratigraphic thickness wavelengths of 5-10 m, but also at shorter,

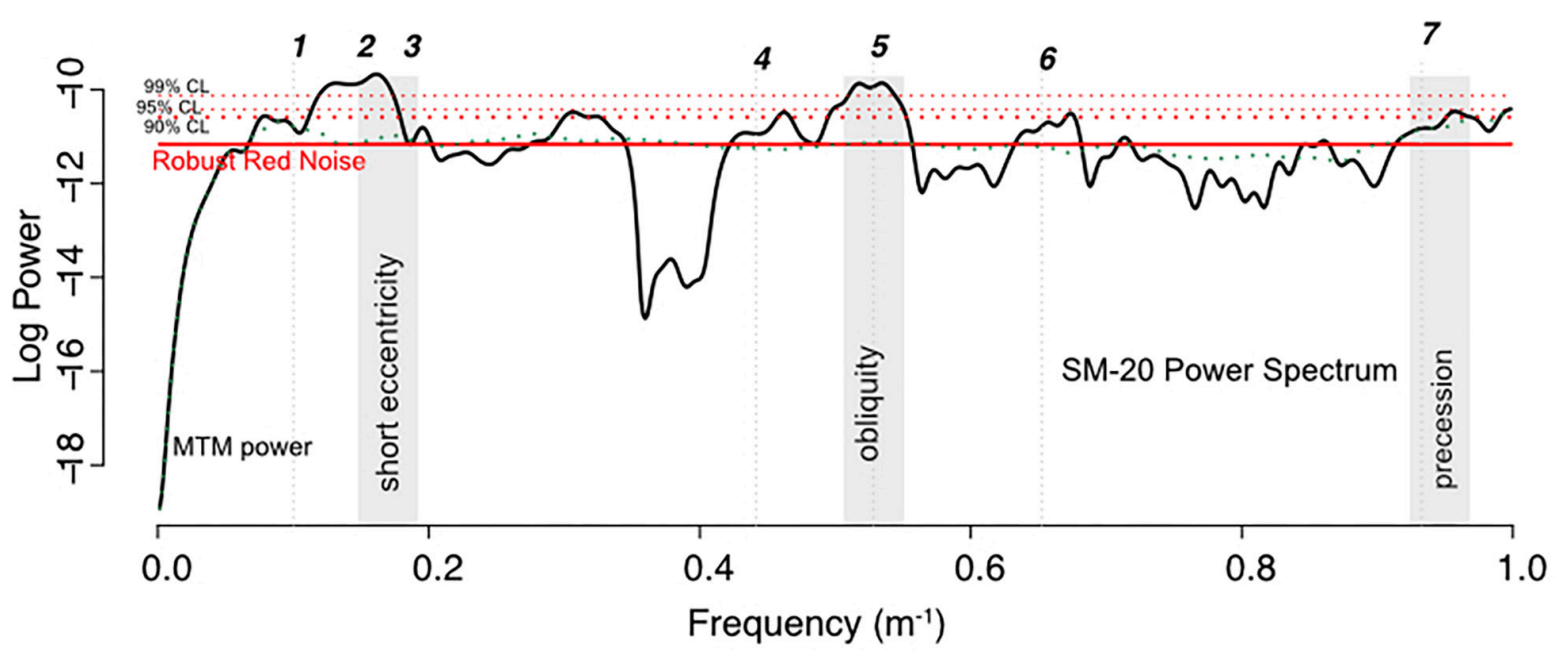

FIGURE 4 | Log power spectrum for the SM-20 portable susceptibility meter magnetic susceptibility time series shown in Figure $\mathbf{3}$ showing significant peaks chosen by Astrochron (Meyers, 2014) and numbered (confidence limit set to 0.9). The shaded bands show our choice for the Milankovitch cycles. See Table $\mathbf{1}$ for the periods/frequencies of the numbered peaks.

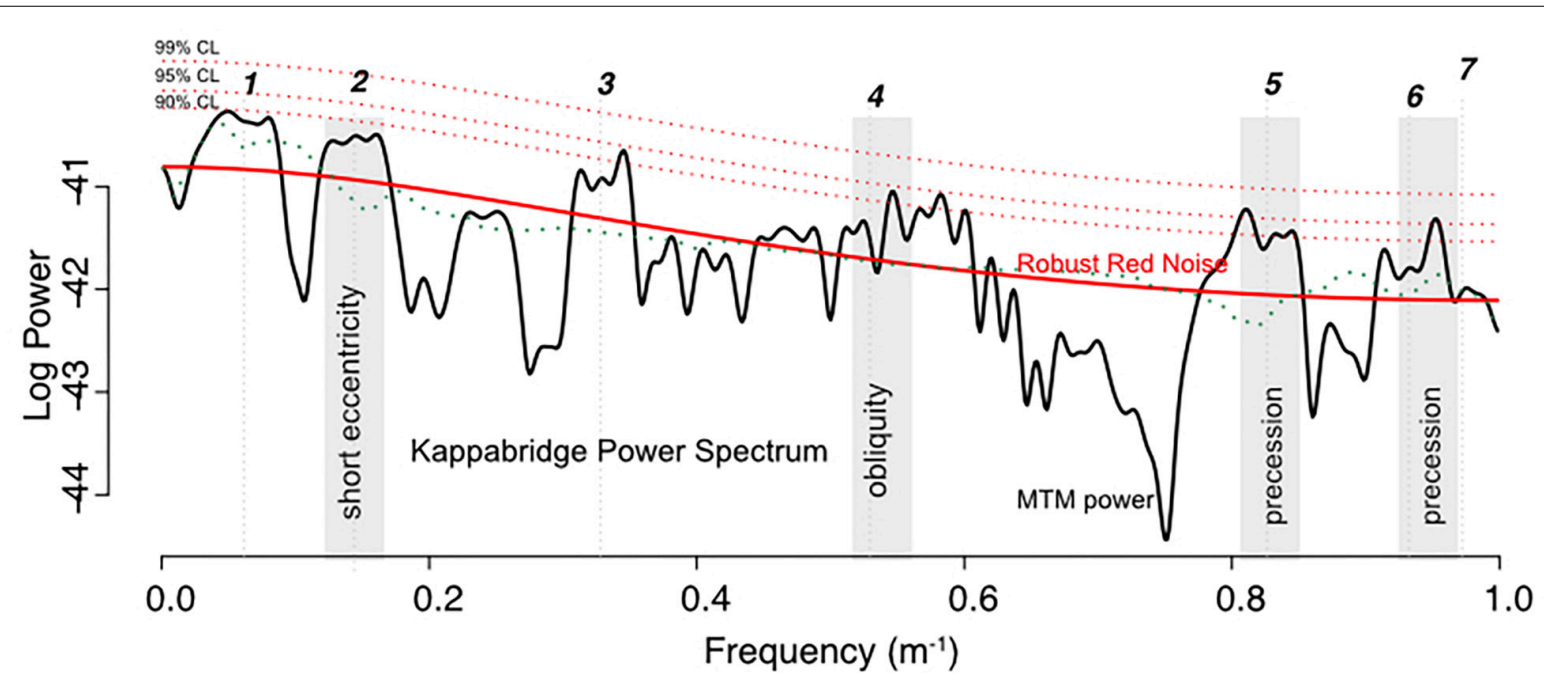

FIGURE 5 | Log power spectrum for the Kappabridge measured magnetic susceptibility time series shown in Figure $\mathbf{3}$ showing significant peaks chosen by Astrochron (Meyers, 2014) and numbered (confidence limit set to 0.85). The shaded bands show our choice for the Milankovitch cycles. See Table 2 for the periods/frequencies of the numbered peaks. 
1-2 $\mathrm{m}$ scales (Figure 2 and Supplementary Table S2). The $\mathrm{IRM}_{3.5 \mathrm{~T}}$ time series shows particularly high amplitude variation at the 1-2 $\mathrm{m}$ wavelength stratigraphic thickness scale. The big low in magnetic intensity for all three datasets at 25-30 m along the section correlates with a large sandstone bed indicating lithologic control of the susceptibility at this spatial scale. MTM spectral analysis using Astrochron of the $\mathrm{IRM}_{3.5 \mathrm{~T}-100 \mathrm{mT}}$ time series shows significant spectral peaks at $6.8 \mathrm{~m}$ stratigraphic thickness (labeled 1) and $1.3 \mathrm{~m}$ stratigraphic thickness (labeled 2) (Figure 2). A third peak at $\sim 1.1 \mathrm{~m}$ stratigraphic thickness (labeled 3) is selected by Astrochron when the confidence level selection criterion is dropped to 0.85 .

For the 2017 dataset, the main study of this paper, the magnetic susceptibility time series for the Kappabridge, laboratory rock sample measurements and the SM-20 portable susceptibility meter measurements both show high amplitude, high frequency $(\sim 1 \mathrm{~m}$ stratigraphic thickness periods) content (Figure 3 and Supplementary Table S1). The Kappabridge time series shows a better correlation with the lithologic column with longer wavelength lows associated with sandstone beds. Both time series show high amplitude, high frequency variability within the mudstone overbank deposits exposed between $5 \mathrm{~m}$ and about $28 \mathrm{~m}$ in the section, indicating that the magnetic susceptibility isn't controlled completely by lithologic variations. Both time series show hierarchical frequency variability, as would be expected for records of different Milankovitch cycles, but the two different time series (SM-20 and Kappabridge) cannot be easily correlated.

A direct comparison of the two time series, including errors bars (one standard deviation), shows that the SM-20 portable susceptibility meter dataset has much higher uncertainty in its measurements. The uncertainty in the SM-20 measurements could be the explanation for the differences in the two time series (Figure 3). Given this obvious difference in the two time series, collected by different types of measurement, it is interesting that for the MTM spectral analyses, Astrochron (Meyers, 2014) picks very similar significant peaks using both robust red noise (Mann and Lees, 1996) and harmonic f-test (Thomson, 1982) as selection criteria, for both series (Figures 4, 5 and Tables 1, 2).

The most striking similarities between the two time series are spectral peaks at $6.8,1.9$, and $1.1 \mathrm{~m}$. The ratio of these peaks is similar to the ratios of short eccentricity $(125 \mathrm{ka})$, obliquity (35 ka), and short precession (17.5 ka) at $330 \mathrm{Ma}$ (Waltham, 2015). Thus, we have tentatively identified these peaks as the short eccentricity, obliquity and precession Milankovitch cycles in the Carboniferous. Note that the $5.45 \mathrm{~m}$ peak in the SM-20 data (Table 1) could be 95 ka short eccentricity, and the $1.21 \mathrm{~m}$ peak in the Kappabridge data (Table 2) could be long precession $(21 \mathrm{ka})$. Note also that the peaks identified from the longer $68 \mathrm{~m}$ section are very similar to those observed for the IRM $\mathrm{I}_{3.5 \mathrm{~T}-100 \mathrm{mT}}$ measured for the $40 \mathrm{~m}$ pilot study. The IRM times series peak at $6.8 \mathrm{~m}$ is identified as short eccentricity, the 1.3 and $1.1 \mathrm{~m}$ peaks are long and short precession.

We can test these picks using average spectral misfit (ASM) in the Astrochron software package (Meyers and Sageman, 2007; Meyers, 2014). It iteratively tries different SARs to fit the selected spectral peak frequencies to Milankovitch target frequencies.
TABLE 1 | Portable SM-20 spectral peaks.

\begin{tabular}{|c|c|c|c|c|c|}
\hline $\begin{array}{l}\text { Peak } \\
\text { number }\end{array}$ & $\begin{array}{l}\text { Frequency } \\
\qquad(1 / \mathrm{m})\end{array}$ & $\begin{array}{c}\text { Period } \\
\text { (m) }\end{array}$ & $\begin{array}{c}\text { Harmonic } \\
\text { CL (\%) }\end{array}$ & $\begin{array}{c}\text { RedNoise } \\
\text { CL (\%) }\end{array}$ & $\begin{array}{c}\text { Target } \\
\text { Milankovitch (ka) }\end{array}$ \\
\hline 1 & 0.1 & 10 & 97.1 & 80.2 & \\
\hline 2 & 0.148 & 6.77 & 94.6 & 99.9 & 125 \\
\hline 3 & 0.184 & 5.45 & 97.7 & 63.8 & 95 \\
\hline 4 & 0.442 & 2.26 & 93.9 & 72.1 & \\
\hline 5 & 0.528 & 1.89 & 90.2 & 99.8 & 35 \\
\hline 6 & 0.652 & 1.53 & 97.0 & 81.2 & \\
\hline 7 & 0.932 & 1.07 & 95.0 & 79.3 & 17.5 \\
\hline
\end{tabular}

Bolded peaks used for average spectral misfit (Figure 6). $C L=$ confidence limit.

TABLE 2 | Laboratory sample - Kappabridge spectral peaks.

\begin{tabular}{lccccc}
\hline $\begin{array}{l}\text { Peak } \\
\text { number }\end{array}$ & $\begin{array}{c}\text { Frequency } \\
(\mathbf{1} / \mathbf{m})\end{array}$ & $\begin{array}{c}\text { Period } \\
(\mathbf{m})\end{array}$ & $\begin{array}{c}\text { Harmonic } \\
\text { CL (\%) }\end{array}$ & $\begin{array}{c}\text { RedNoise } \\
\text { CL (\%) }\end{array}$ & $\begin{array}{c}\text { Target } \\
\text { Milankovitch (ka) }\end{array}$ \\
\hline 1 & 0.06 & 16.2 & 87.7 & 85.6 & \\
$\mathbf{2}$ & $\mathbf{0 . 1 4 4}$ & $\mathbf{6 . 9 4}$ & $\mathbf{9 5 . 9}$ & $\mathbf{8 3 . 6}$ & $\mathbf{1 2 5}$ \\
3 & 0.328 & 3.05 & 96.5 & 81.4 & \\
$\mathbf{4}$ & $\mathbf{0 . 5 2 9}$ & $\mathbf{1 . 8 9}$ & $\mathbf{9 9 . 0}$ & $\mathbf{7 0 . 0}$ & $\mathbf{3 5}$ \\
$\mathbf{5}$ & $\mathbf{0 . 8 2 6}$ & $\mathbf{1 . 2 1}$ & $\mathbf{9 1 . 9}$ & $\mathbf{8 6 . 3}$ & $\mathbf{2 1}$ \\
$\mathbf{6}$ & $\mathbf{0 . 9 3 2}$ & $\mathbf{1 . 0 7}$ & $\mathbf{9 7 . 8}$ & $\mathbf{7 7 . 3}$ & $\mathbf{1 7 . 5}$ \\
7 & 0.972 & 1.03 & 98.8 & 63.4 & \\
\hline
\end{tabular}

Bolded peaks used for average spectral misfit (Figure 6). CL = confidence limit.

It tests the significance level of the null hypothesis for the best fit SAR (Meyers, 2014). ASM gives statistically significant fits, at greater than $98 \%$, for both the SM-20 series and the Kappabridge time series yielding the identical SAR of $5.69 \mathrm{~cm} / \mathrm{ka}$ for both time series (Figure 6).

Finally, we can test our Milankovitch picks by conducting an AM test of the precession (17.5 ka) cycle we have identified in our spectral analysis. Precession should be modulated by eccentricity, so if we picked precession correctly its amplitude should be modulated by the frequency we have selected as eccentricity. Astrochon (Meyers, 2014) provides a testPrecession routine that could accomplish this test, however, an accurate theoretical model of precession is needed. This exists only as far back in time as the Paleogene, therefore, we conducted our own version of this test. We filtered the Kappabridge rock sample time series at $0.93 \mathrm{~m}^{-1}$ (the $1.07 \mathrm{~m}$ spectral peak) and the resulting filtered series showed AM with six peaks per pulse (Figure 7). We conducted MTM spectral analysis on the amplitude envelope of the filtered series and found a strong peak with a frequency of $0.14 \mathrm{~m}^{-1}$, which is exactly the $125 \mathrm{ka}$ eccentricity peak we targeted with our ASM analysis. The AM test shows that we have correctly selected precession and eccentricity in our spectral analysis.

Evolutionary spectrograms of the portable (SM-20) and laboratory-measured rock samples (Kappabridge) time series (Figure 8) show that for the portable susceptibility meter data all three of the Milankovitch cycles are stronger in the upper part of the section, starting at about $30 \mathrm{~m}$ for the short eccentricity and obliquity, but only at about $40 \mathrm{~m}$ 
A

Null Hypothesis Significance Level

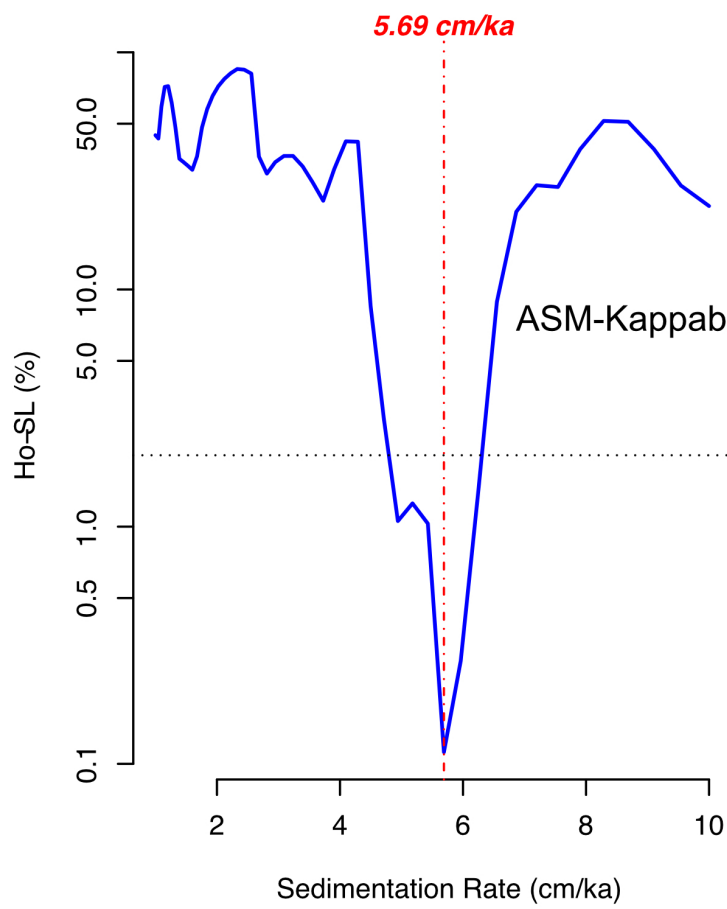

C

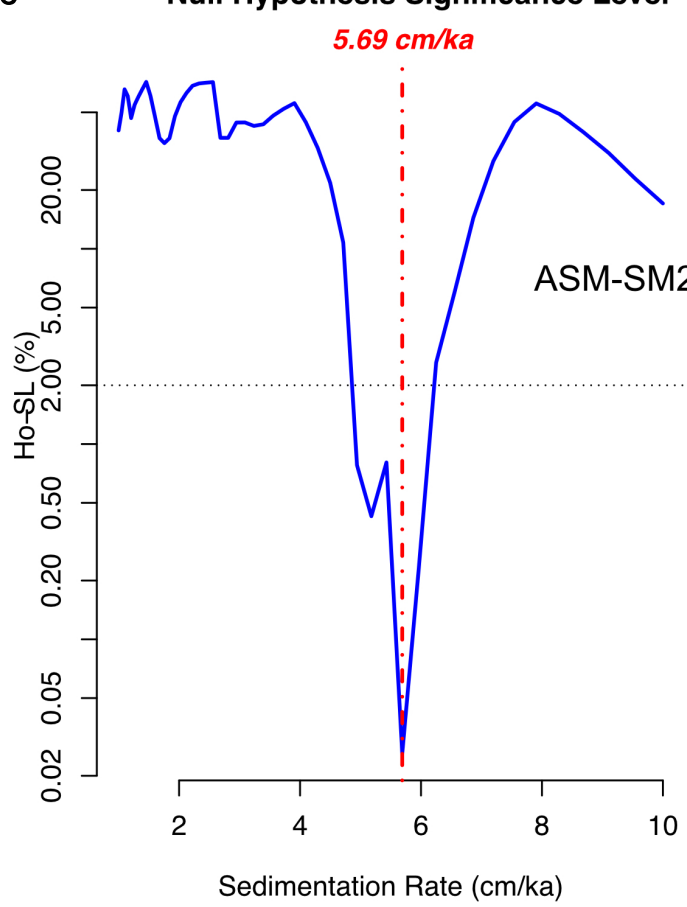

B

Data (black) vs. Target (red)

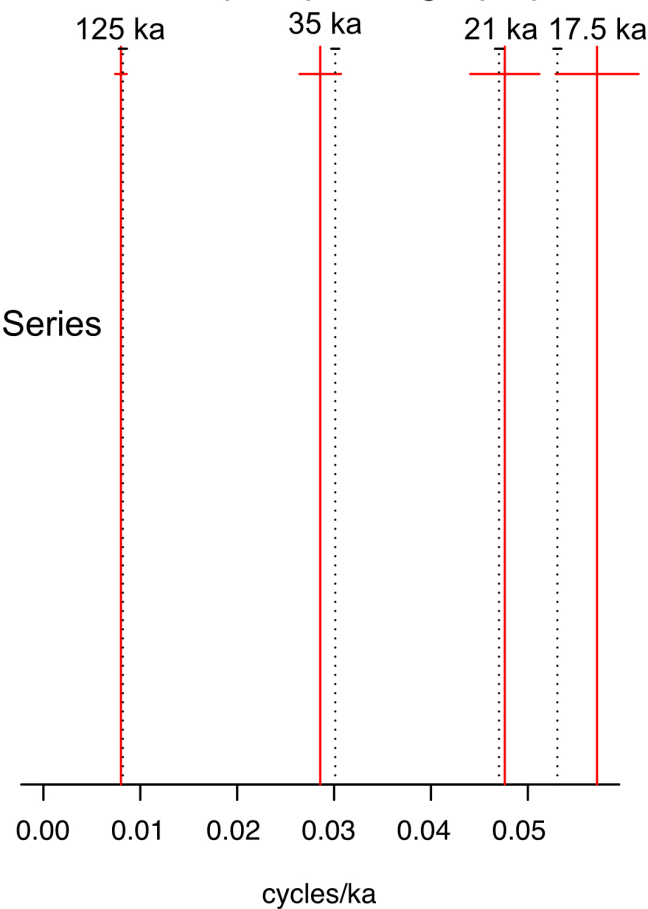

D Data (black) vs. Target (red)

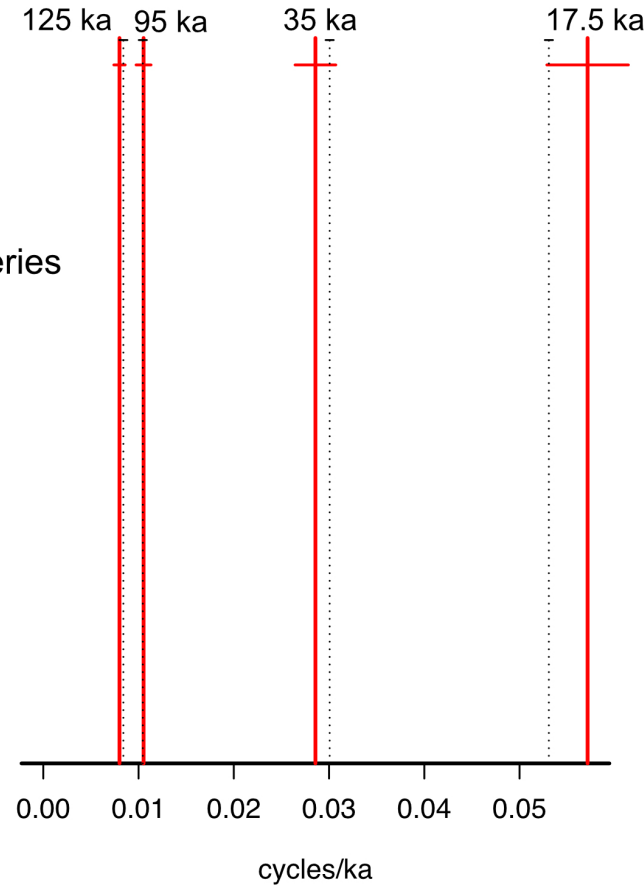

FIGURE 6 | Average spectral misfit (ASM; Meyers and Sageman, 2007) results for the Kappabridge (A) and SM-20 (B) spectral peaks targeted to eccentricity, obliquity, and precession at $330 \mathrm{Ma}$. The significant fit for the two different time series indicates an identical sediment accumulation rate of $5.69 \mathrm{~cm} / \mathrm{ka}$. In panels (C) and (D), the dotted black lines are the data and the red solid lines are the target Milankovitch frequencies.

for the precession cycle. For the Kappabridge-measured rock samples (Figure 8) the eccentricity cycles (both long and short eccentricity, 405 and $100 \mathrm{ka}$ ) are strong throughout the section while obliquity and precession [both long (21 ka) and short $(17.5 \mathrm{ka})]$ vary in strength throughout the section. The most important observation is that the SAR doesn't 

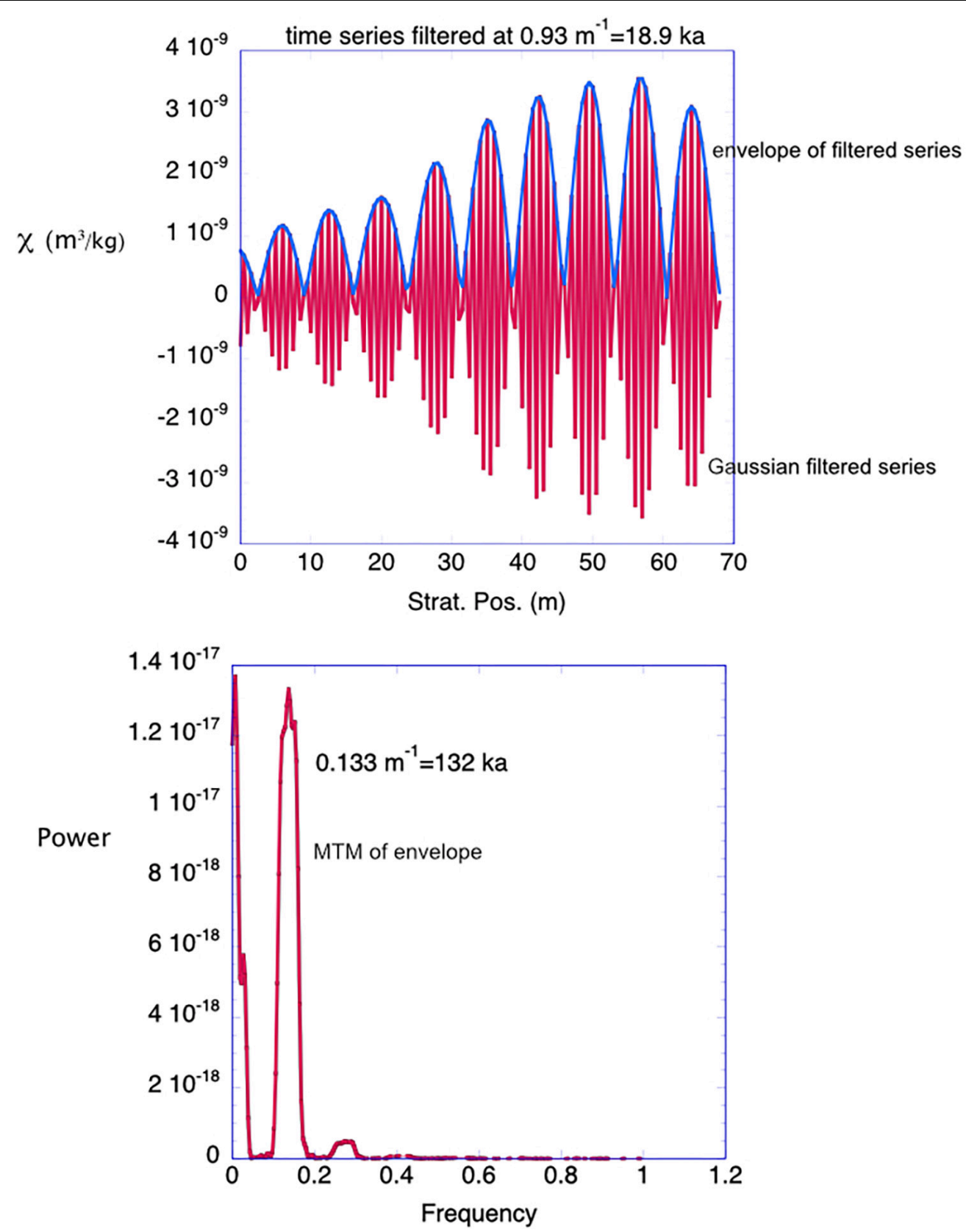

FIGURE 7 | Amplitude modulation (AM) test conducted on the frequency chosen for precession in our results. (Top) The Kappabridge time series was filtered at the frequency of the spectral peak chosen to be precession $\left(0.93 \mathrm{~m}^{-1}\right)$ and the envelope of the amplitude variation yields a power spectrum (Bottom) with a significant peak at the frequency we have chosen as short eccentricity $\left(0.133 \mathrm{~m}^{-1}\right)$. This result strongly supports our assignment of Milankovitch frequencies to the spectral peaks observed in our data.

appear to change throughout the section. The evolutionary spectrograms are compared to the MTM power spectra for each time series. These spectra were calculated by the SSAMTM toolkit (Ghil, 1997) with robust red noise (Mann and Lees, 1996) and are identical to the power spectra calculated from Astrochron (Figure 5); however, using Astrochron's selection criteria (robust red noise and harmonic f-test) the peak labeled long eccentricity (le) has a wavelength of only
$10 \mathrm{~m}$, which would only be $175.7 \mathrm{ka}$ for the $5.69 \mathrm{~cm} / \mathrm{ka}$ SAR calculated by ASM and would not be consistent with long eccentricity, $405 \mathrm{ka}$. However, the maximum amplitude of the le peak yields a wavelength of $22.5 \mathrm{~m}$, indicating a period of $395.4 \mathrm{ka}$ for an SAR of $5.69 \mathrm{~cm} / \mathrm{ka}$, entirely consistent with long eccentricity. Therefore, the Kappabridge time series also contains a record of long eccentricity which repeats approximately three times in our record. The $40 \mathrm{~m}$ 

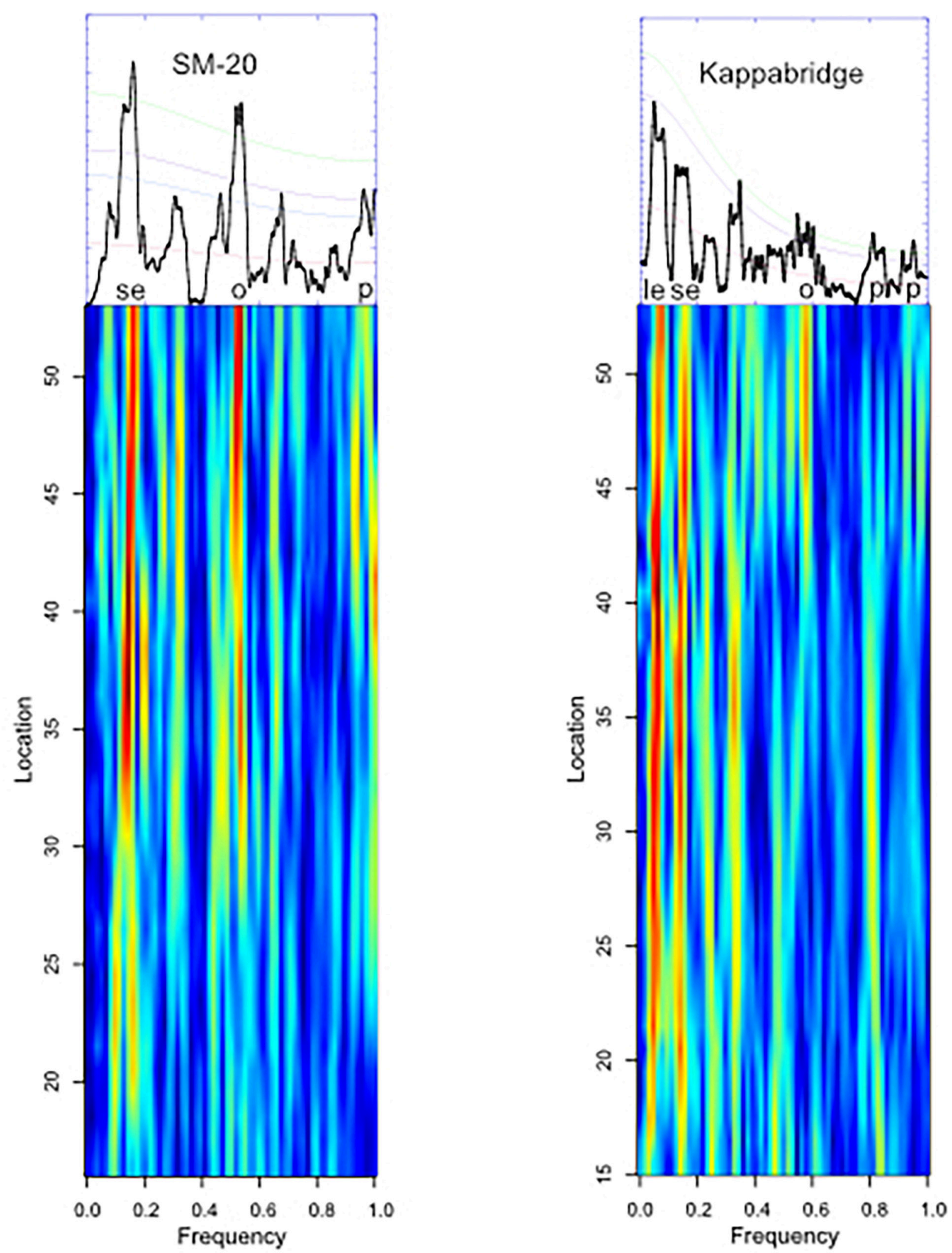

FIGURE 8 | Evolutionary spectrograms calculated using Astrochron (Meyers, 2014) for the SM-20 (Left) and the Kappabridge measured samples (Right). The MTM calculated power spectrum for each series (using SSA-MTM) is shown at the top of each evolutionary spectrogram with Milankovitch spectral peaks labeled (le = long eccentricity, $\mathrm{se}=$ short eccentricity, $\mathrm{O}=$ obliquity, $\mathrm{p}=$ precession). The evolutionary spectrograms were calculated with a window of $30 \mathrm{~m}$ and a step of $1 \mathrm{~m}$. They show that the sediment accumulation rate does not vary significantly through the section although the power of the different frequencies does vary. 


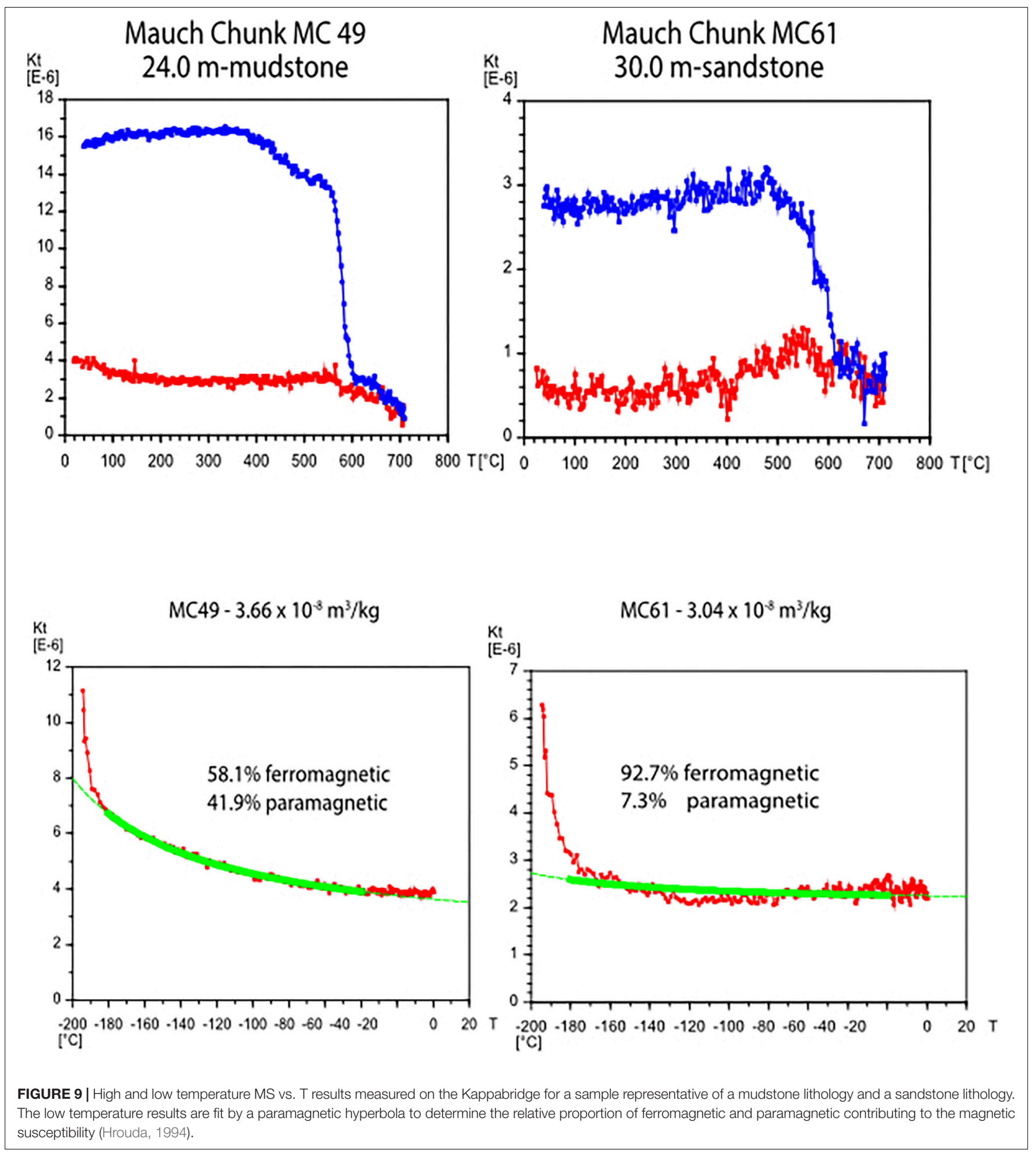

IRM time series collected in 2012 is too short to observe long eccentricity.

\section{Rock Magnetics}

The MS vs. T plots measured at temperatures between 20 and $700^{\circ} \mathrm{C}$ indicate the weak occurrence of magnetite but mainly the presence of hematite in the Mauch Chunk Formation samples (Figure 9). On cooling from high temperatures the strong increase in susceptibility at $580^{\circ} \mathrm{C}$ indicates that magnetite has been created by the heating. This behavior is observed for both a mudstone and a sandstone sample. The low temperature MS vs. $\mathrm{T}$ plots measured at temperatures between -195 and $0^{\circ} \mathrm{C}$ 

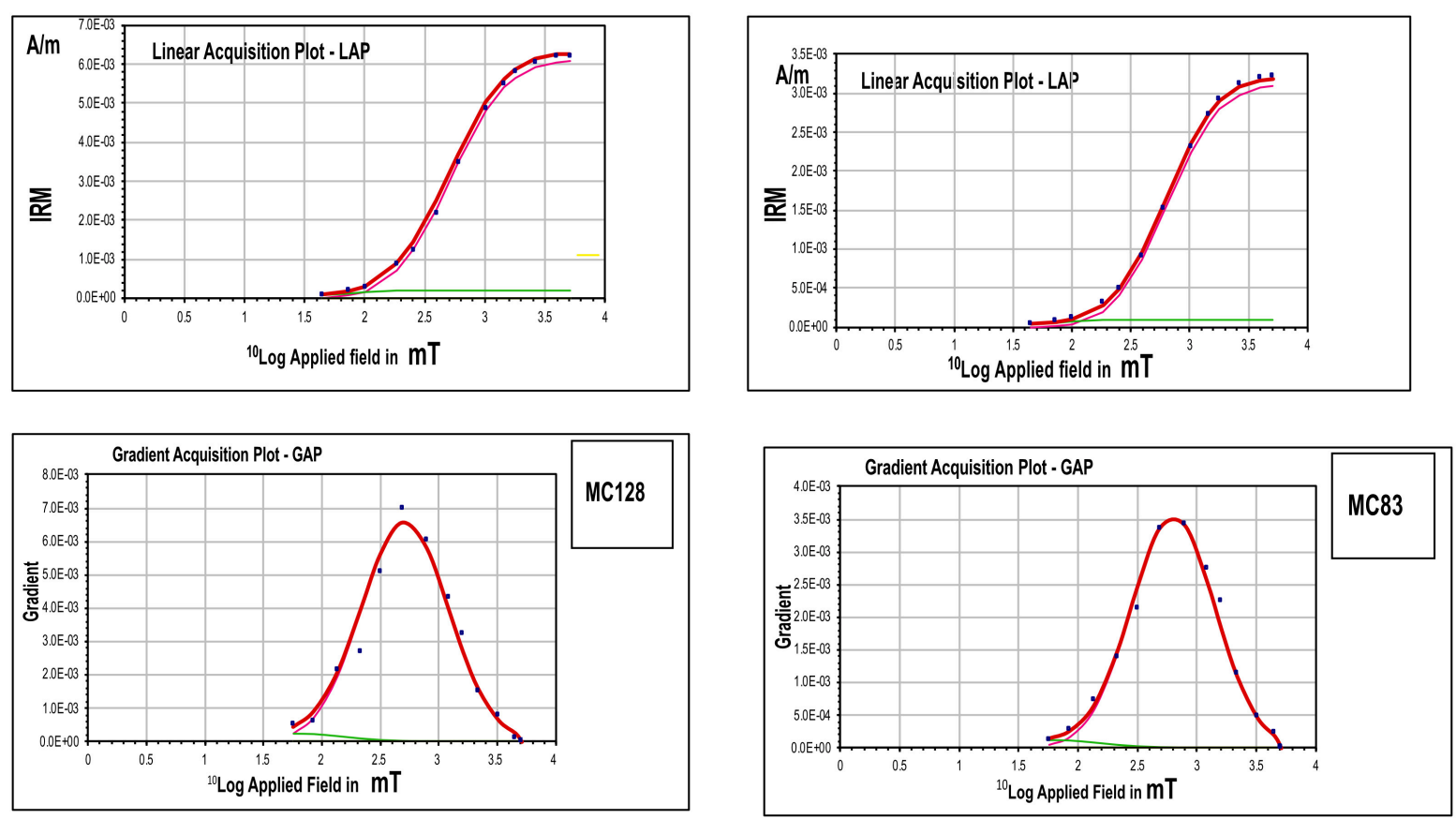

FIGURE 10 | Isothermal remanent magnetization acquisition results showing that the samples are dominated by a high coercivity remanence that saturates by $3.5 \mathrm{~T}$ and is probably hematite. There is a minor contribution from a lower coercivity component that is probably magnetite.

show no evidence of a Verwey transition, so magnetite is not present in any great abundance (Figure 9). These results are supported by the IRM acquisition experiments (Figure 10) which show that the IRM for the Mauch Chunk Formation samples saturates at about $3 \mathrm{~T}$. Modeling of the IRM acquisition data shows that most (97\%) of the IRM acquisition data could be fit with a coercivity component of about $0.5-0.6 \mathrm{~T}$ indicating a high coercivity mineral, most likely hematite. A very small component ( $\sim 3 \%$ of the IRM) could be fit with a low coercivity $(65 \mathrm{mT})$ mineral, probably a small amount of magnetite.

The relative proportion of ferromagnetic (hematite) and paramagnetic (clay) contributing to the bulk susceptibility was estimated for 21 samples over a $10 \mathrm{~m}$ stratigraphic interval between 20.5 and $30.5 \mathrm{~m}$ in the section. The stratigraphic interval included both the red mudstone overbank deposits and the sandstone channel deposits. An example of the hyperbola fit to the low temperature measurements for a mudstone and a sandstone sample to estimate paramagnetic/ferromagnetic content is shown in Figure 9. The contribution of paramagnetic and ferromagnetic to the total susceptibility was determined by multiplying the percentage of each by the bulk susceptibility for a sample (Figure 11). Two repeated measurements for both a mudstone and a sandstone sample show the percentage estimates are repeatable within about $7 \%$ points. The high frequency peaks in bulk susceptibility with a wavelength of 1-2 $\mathrm{m}$ are driven mainly by variations in the ferromagnetic minerals. The ferromagnetic minerals are the only contributor to the bulk susceptibility in the sandstone (Figure 11). The paramagnetic minerals also drive some of the peaks in the bulk susceptibility. They are sometimes in phase with the ferromagnetic mineral variations and sometimes out of phase. In the $10 \mathrm{~m}$ stratigraphic interval measured for this analysis, there are six ferromagnetic peaks which match the six peaks in the bulk susceptibility, suggesting a wavelength of $\sim 1.5 \mathrm{~m}$, whereas the paramagnetic minerals show two large peaks in phase with the ferromagnetic peaks and possibly an additional two smaller peaks that do not coincide with peaks in the bulk susceptibility. When these estimates of stratigraphic wavelength are compared to the spectral analysis of the Kappabridge time series (Table 2), it strongly suggests that ferromagnetic mineral concentration variations are a strong control on the bulk MS variations that record astronomically forced climate change (Milankovitch) cycles at precession (20 ka) and obliquity (35 ka) frequencies. Given the $10 \mathrm{~m}$ length of the stratigraphic interval used for this analysis, it is not possible to determine if ferromagnetic or paramagnetic minerals are beating at the eccentricity period of $\sim 7 \mathrm{~m}$.

\section{DISCUSSION}

\section{Recording Milankovitch Cycles}

The MS time series collected with the SM-20 portable susceptibility meter and the Kappabridge measurement of rock samples both showed a record of Milankovitch cycles at periods of 100,35 , and $20 \mathrm{ka}$ and the IRM time series showed Milankovitch cycles at 100 and $20 \mathrm{ka}$. ASM analysis (Meyers, 2014) of both the portable and Kappabridge MS time series indicate a SAR of $5.69 \mathrm{~cm} / \mathrm{ka}$ showing that the 5-7 m wavelength peaks are short eccentricity at 125 and $95 \mathrm{ka}$, the $1.9 \mathrm{~m}$ peak 


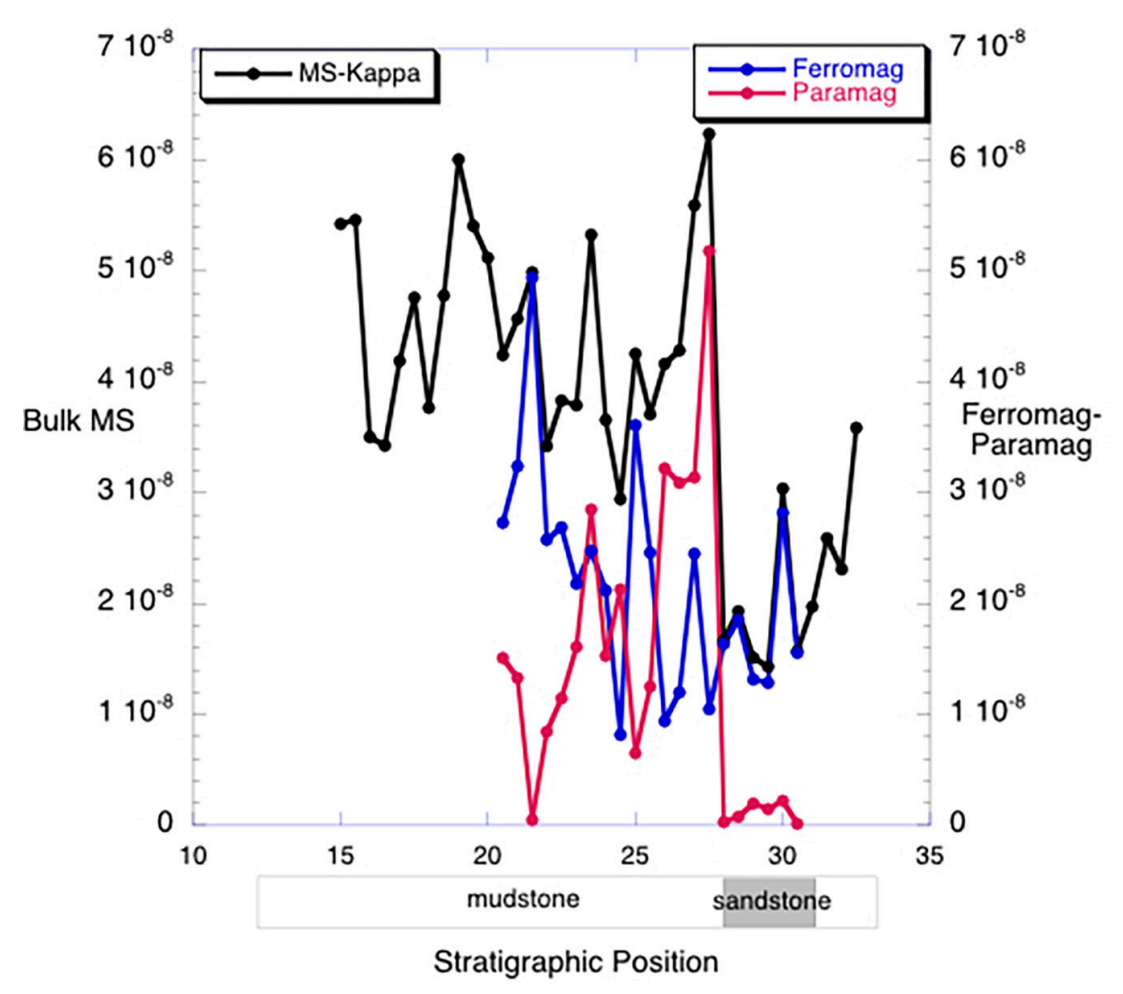

FIGURE 11 | The relative proportion of ferromagnetic minerals (blue curve) and paramagnetic minerals (red curve) contributing to the bulk susceptibility (black curve) for $10 \mathrm{~m}$ between 20.5 and $30.5 \mathrm{~m}$ in the section. The percentages determined from the low temperature MS vs. T measurements have been multiplied by the bulk susceptibility for a sample to determine the susceptibility for each magnetic mineral type. Note that the blue (ferromagnetic) curve follows all the short period peaks in the bulk susceptibility curve (black curve) indicating that the ferromagnetic mineral variations are the source of the bulk susceptibility variations. The paramagnetic mineral contribution is sometimes in phase with the ferromagnetic variations, sometimes out of phase. The magnetic susceptibility of the sandstone bed is almost all due to ferromagnetic minerals.

is obliquity at $35 \mathrm{ka}$, and the $1.2-1.1 \mathrm{~m}$ wavelength peaks are precession at 21 and $17.5 \mathrm{ka}$. AM analysis shows that the $1.07 \mathrm{~m}$ wavelength peak, picked to be short precession at $17.5 \mathrm{ka}$, is modulated by a frequency of about 0.14 cycles $/ \mathrm{m}$ which is our pick for short eccentricity at $125 \mathrm{ka}$. This result supports our pick for Milankovitch cycles in the data.

Our results indicate that a fluvial, terrigenous depositional environment can record Milankovitch global climate cycles despite the expectation that this type of environment will experience discontinuous sedimentation (i.e., flooding into the overbank environment) and the effects of environmental shredding (Jerolmack and Paola, 2010) due to landscape processes, such as avulsion (channel migration). Our results would suggest, in light of Jerolmack and Paola's analysis, that the shortest Milankovitch cycle recorded (i.e., precession at $17.5 \mathrm{ka}$ ) is still a longer period than shredding processes in the depositional basin (e.g., flooding and avulsion).

The SAR derived from these high resolution chronostratigraphy results suggests that the long normal polarity interval of the Earth's geomagnetic field recorded at the Pottsville section and correlated throughout eastern North America (Opdyke et al., 2014) is 1.75 million years in duration and not 1.0 million years as suggested by biostratigraphy (Opdyke et al., 2014) and may help more accurately calibrate this part of the geologic time scale in the Carboniferous (Gradstein et al., 2012).

\section{Encoding the Milankovitch Signal}

The strong positive correlation between the percentage of ferromagnetic minerals contributing to the magnetic susceptibility and the bulk susceptibility variations suggests erosion in the source area, driven by climate change, is adding more or less depositional hematite to a background of either clay minerals or quartz sand in the depositional basin at the Milankovitch time scales. Therefore, changes in the source area for the Mauch Chunk sediments are encoding the Milankovitch cycles rather than changes in the depositional basin. This is similar to the record of Milankovitch cycles in marine sediments in which variations in precipitation on the continent changes the supply of clastic sediments into a background of carbonate production in the near-shore marine environment (Kodama et al., 2010; Gong et al., 2017; Minguez and Kodama, 2017). The record of eccentricity and precession by the Mauch Chunk Formation sediments is consistent with its $23^{\circ} \mathrm{S}$ paleolatitude (Bilardello and Kodama, 2010) where the strength of the monsoon is driven by eccentricity and precession. However, it is interesting that rock magnetics also detect obliquity for this low paleolatitude because obliquity insolation variations are stronger 
at high latitudes than low latitudes. In support of our results, Gunderson et al. (2012) did observe a strong obliquity signal in Mediterranean (low latitude) Plio-Pleistocene sediments recorded by magnetic susceptibility. The weak coupling of paramagnetic minerals to the shorter Milankovitch frequencies could be due to variations in chemical weathering in the source area being driven by global climate change.

\section{Portable Susceptibility Meter Measurements}

Even though the portable susceptibility meter measurements did not observe exactly the same time series as the more accurate Kappabridge measurements of rock samples, and could not be normalized by sample mass, the spectral analysis of the portable time series was still able to detect the same Milankovitch cycles as the Kappabridge-rock sample measurements. This result indicates that using the portable susceptibility meter for rock magnetic cyclostratigraphy is a valid method for constructing a time series, particularly for clastic, relatively high magnetic mineral content, sedimentary rocks. Conceivably, the portable susceptibility measurements could be used for reconnaissance work to accurately set the sampling interval for more detailed sample collection and rock magnetic measurements in the laboratory.

\section{CONCLUSION}

Both measurements in the field using a portable susceptibility meter and magnetic susceptibility and IRM measurement of rock samples in the laboratory could detect Milankovitch cycles in a fluvial depositional environment recorded by depositional hematite grains in red beds deposited during the Carboniferous. This is an important result because it opens up terrestrial, fluvial deposits to the high-resolution dating and correlation afforded by rock magnetic cyclostratigraphy.

A SAR of $5.69 \mathrm{~cm} / \mathrm{ka}$ derived from both the portable susceptibility meter and the rock sample measurements suggests that the long normal polarity interval in the Pottsville Mauch Chunk Formation section is 1.75 million years in duration, not $<1$ million years as previously indicated by the biostratigraphy and suggests a slight recalibration of this part of the Carboniferous geologic time scale is needed.

The astronomically forced, Milankovitch-scale climate cycles were probably encoded by variations in erosion of the source

\section{REFERENCES}

Abdul Aziz, H., Hilgen, F., Krijgsman, W., Sanz, E., and Calvo, J. P. (2000). Astronomical forcing of sedimentary cycles in the middle to late miocene continental Calatayud Basin (NE Spain). Earth Planet. Sci. Lett. 177, 9-22. doi: $10.1016 / \mathrm{s} 0012-821 \times(00) 00035-2$

Abels, H. A., Kraus, M. J., and Gingerich, P. D. (2013). Precession-scale cyclicity in the lower eocene fluvial willwood formation of the bighorn basin. Wyoming (USA). Sedimentology 60, 1467-1483.

Berger, A., and Loutre, M. F. (1994). Astronomical forcing through geological time. Spec. Publs. Int. Assoc. Sediment 19, 15-24. doi: 10.1002/9781444304039.ch2 area supplying varying amounts of depositional hematite into a background of paramagnetic clay minerals or diamagnetic quartz sand in the depositional basin.

\section{DATA AVAILABILITY STATEMENT}

The raw data supporting the conclusion of this manuscript will be made available by the author, without due reservation, to any qualified researcher. The susceptibility measurements are available in the Supplementary Material.

\section{AUTHOR CONTRIBUTIONS}

KK made susceptibility measurements, helped to collect the samples, analyzed the data, and wrote the manuscript.

\section{FUNDING}

This study was partially supported by NSF-EAR 1322002.

\section{ACKNOWLEDGMENTS}

Marta Sanchez Anson collected the $68 \mathrm{~m}$ section, measured in situ susceptibilities with the portable susceptibility meter, prepared the laboratory samples for measurement, and made some of the Kappabridge measurements. Daniel Minguez and Nathan Hopkins collected the 2012 samples for the pilot study and made the laboratory measurements of IRM and susceptibility.

\section{SUPPLEMENTARY MATERIAL}

The Supplementary Material for this article can be found online at: https://www.frontiersin.org/articles/10.3389/feart. 2019.00285/full\#supplementary-material

TABLE S1 | Laboratory Kappabridge and portable SM-20 susceptibility measurements for the Pottstown section of the Mauch Chunk Formation.

TABLE S2 | IRM (3.5 T), IRM (3.5 T demagnetized at $100 \mathrm{mT}$ ), and magnetic susceptibility measurements (kappabridge) for the 2012 study of the Mauch Chunk Formation at the Pottsville section.

Bilardello, D. A., and Kodama, K. P. (2010). A new inclination shallowing correction of the mauch chunk formation of pennsylvania, based on high-field AIR results: implications for the carboniferous north american APW path and pangea reconstructions. Earth Planet. Sci. Lett. 299, 218-227. doi: 10.1016/j. epsl.2010.09.002

Cioppa, M. T., and Kodama, K. P. (2003). Evaluation of paleomagnetic and finite strain relationships due to the alleghanian orogeny in the mississippian mauch chunk formation, pennsylvania. J. Geophys. Res. 108, 1-16.

DiVenere, V. J., and Opdyke, N. D. (1991). Magnetic polarity stratigraphy in the uppermost mississippian mauch chunk formation pottsville, pennsylvania. Geology 19, 127-130. 
Ghil, M. (1997). “The SSA-MTM toolkit: applications to analysis and prediction of time series," in Proceedings of Optical Science, Engineering and Instrumentation, San Diego, CA.

Gilman, D., Fuglister, R., and Mitchell, J. Jr. (1963). On the power spectrum of "red noise". J. Atmos. Sci. 20, 182-184. doi: 10.1175/1520-0469(1963)020<0182: otpson>2.0.co;2

Gong, Z., Kodama, K. P., and Li, Y.-X. (2017). Rock magnetic cyclostratigraphy of the doushantuo formation. Precambrian Res. 289, 62-74.

Gradstein, F. M., Ogg, J. G., Schmitz, M. D., and Ogg, G. M. (eds) (2012). The Geologic Time Scale 2012 (Oxford: Elsevier), 1144.

Gunderson, K. L., Kodama, K. P., Anastasio, D. J., and Pazzaglia, F. J. (2012). Rock magnetic cyclostratigraphy for the late pliocene-early pleistocene stirone section. Geol. Soc. Lond. Spec. Publ. 373, 309-323. doi: 10.1144/SP 373.8

Hinnov, L. A. (2013). Cyclostratigraphy and its revolutionizing applications in the earth and planetary sciences. Geol. Soc. Am. Bull. 125, 1703-1734. doi: 10.1130/B30934.1

Hrouda, F. (1994). A technique for the measurement of thermal changes of magnetic susceptibility of weakly magnetic rocks by the CS-2 apparatus and KLY-2 Kappabridge. Geophys. J. Int. 118, 604-612. doi: 10.1111/j.1365-246x. 1994.tb03987.x

Jerolmack, D. J., and Paola, C. (2010). Shredding of environmental signals by sediment transport. Geophys. Res. Lett. 37:L19401.

Kent, D. V., and Opdyke, N. D. (1985). Multicomponent magnetizations from the mississippian mauch chunk formation of the central appalachians and their tectonic implications. J. Geophys. Res. 90, 5371-5383. doi: 10.1029/ jb090ib07p05371

Kodama, K. P., Anastasio, D. J., Newton, M. L., Pares, J., and Hinnov, L. A. (2010). High resolution rock magnetic cyclostratigraphy in an eocene flysch, spanish pyrenees. Geochem. Geophys. Geosys. 11:Q0AA07. doi: 10.1029/2010GC00 3069

Kodama, K. P., and Hinnov, L. A. (2015). Rock Magnetic Cyclostratigraphy. Blackwell: Wiley, 165.

Kruiver, P. P., Dekkers, M. J., and Heslop, D. (2001). Quantification of magnetic coercivity components by the analysis of acquisition curves of isothermal remanent magnetization. Earth Planet. Sci. Lett. 189, 269-276. doi: 10.1016/ s0012-821x(01)00367-3

Levine, J. R., and Slingerland, R. (1987). Upper mississippian to middle pennsylvanian stratigraphic section. Geol. Soc. Am. Centen. 15, 59-63.

Mann, M., and Lees, J. (1996). Robust estimation of background noise and signal detection in climatic time series. Clim. Chang. 33, 409-445. doi: 10.1007/ BF00142586

Meyers, S. R. (2012). Seeing red in cyclic stratigraphy: spectral noise estimation for astrochronology. Paleoceanogr. Paleoclimatol. 27:PA3228. doi: 10.1029/ 2012PA002307

Meyers, S. R. (2014). Astrochron: an R Package for Astrochronology. Available at http://cran.r-project.org/package=astrochron
Meyers, S. R., and Sageman, B. B. (2007). Quantification of deep-time orbital forcing by average spectral misfit. Am. J. Sci. 307, 773-792. doi: 10.2475/05. 2007.01

Minguez, D., and Kodama, K. P. (2017). Rock magnetic chronostratigraphy of the shuram carbon isotope excursion: wonoka formation. Aust. Geol. 45, 567-570. doi: $10.1130 / \mathrm{g} 38572.1$

Minguez, D., Kodama, K. P., and Hillhouse, J. W. (2015). Paleomagnetic and cyclostratigraphic constraints on the synchroneity and duration of the shuram carbon isotope excursion, johnnie formation, death valley region, CA. Precambrian Res. 266, 395-408. doi: 10.1016/j.precamres.2015.05.033

Noorbergen, L. J., Abels, H. A., Hilgen, F. J., Robson, B. E., Jong, E. D., Dekkers, M. J., et al. (2018). Conceptual models for short-eccentricity climate control on peat formation in a lower Palaeocene fluvial system, northeaster montana (USA). Sedimentology 65, 775-808. doi: 10.1111/sed.12405

Opdyke, N. D., Giles, P. S., and Utting, J. (2014). Magnetic polarity stratigraphy and palynostratigraphy of the mississippian-pennsylvanian boundary interval in eastern north america and the age of the beginning of the kiaman. Geol. Soc. Am. Bull. 126, 1068-1083. doi: 10.1130/b30953.1

Pas, D., Hinnov, L., Day, J. E., Kodama, K., Sinnesael, M., and Liu, W. (2018). Cyclostratigraphic calibration of the famennian stage (Late Devonian, Illinois Basin, USA), Earth Planet. Sci. Lett. 488, 1-13.

RStudio Team. (2015). Rstudio: Integrated Development for R. Boston, MA: RStudio, Inc.

Stamatakos, J., and Kodama, K. P. (1991). Flexural flow folding and the paleomagnetic fold test: an example of strain reorientation of remanence in the mauch chunk formation. Tectonics 10, 807-819. doi: 10.1029/91tc00366

Thomson, D. J. (1982). Spectrum estimation and harmonic analysis. Proc. IEEE 70, 1055-1096. doi: 10.1109/proc.1982.12433

Waltham, D. (2015). Milankovitch period uncertainties and their impact on cyclostratigraphy. J. Sediment. Res. 85, 990-998. doi: 10.2110/jsr.2015.66

Wu, H., Zhang, S., Feng, Q., Jiang, G., Li, H., and Yang, T. (2012). Milankovitch and sub-milankovitch cycles of the early triassic daye formation. Gondwana Res. 22, 748759. doi: 10.1016/j.gr.2011.12.003

Zhang, R., Li, L., Nai, W., Gu, Y., Huang, C., Ogg, J., et al. (2019). Astronomical forcing of terrestrial climate recorded in the pleistocene of the western tarim basin. Palaeoclimatol. Palaeoecol. 530, 78-89. doi: 10.1016/j.palaeo.2019.05.039

Conflict of Interest: The author declares that the research was conducted in the absence of any commercial or financial relationships that could be construed as a potential conflict of interest.

Copyright (c) 2019 Kodama. This is an open-access article distributed under the terms of the Creative Commons Attribution License (CC BY). The use, distribution or reproduction in other forums is permitted, provided the original author(s) and the copyright owner(s) are credited and that the original publication in this journal is cited, in accordance with accepted academic practice. No use, distribution or reproduction is permitted which does not comply with these terms. 